\title{
REVIEW
}

\section{Intestinal Stricture in Crohn's Disease}

\author{
Chen-Wang Chang ${ }^{1}$, Jau-Min Wong ${ }^{2}$, Chien-Chih Tung ${ }^{3}$, I-Lun Shih ${ }^{4}$, Horng-Yuan Wang ${ }^{1}$, Shu-Chen Wei ${ }^{2}$ \\ Department of Gastroenterology, Mackay Memorial Hospital, Taipei; Mackay Junior College of Medicine, Nursing and Management, Taipei; \\ Mackay Medical College, New Taipeil, Departments of Internal Medicine, Integrated Diagnostics and Therapeutics, Medical Imaging, \\ National Taiwan University Hospital and College of Medicine, Taipei, Taiwan
}

Crohn's disease (CD) is a disease with chronic inflammation of unknown etiology involving any part of the gastrointestinal tract. The incidence and prevalence of CD are increasing recently in Asia. Half of the CD patients will have intestinal complications, such as strictures or fistulas, within 20 years after diagnosis. Twenty-five percentage of CD patients have had at least one small bowel stricture and $10 \%$ have had at least one colonic stricture and lead to significant complications. Most of these patients will require at least one surgery during their lifetime. Early diagnosis and evaluation with adequate managements for the patients can prevent disability and mortality of these patient. Here, we reviewed the current incidence of CD with stricture, the etiology of stricture, and how to diagnose and manage the stricture. (Intest Res 2015;13:19-26)

Key Words: Crohn disease; Constriction, pathologic; Intestines; Diagnosis; Disease management

\section{INTRODUCTION}

Crohn's disease (CD), an IBD, is the chronic inflammation of unknown etiology involving any part of the gastrointestinal tract. The incidence and prevalence of CD are lower in Asia than in the west, but both have been increasing over the last four decades. ${ }^{1}$

Based on the Montreal classification system, the behaviors of CD can be divided into nonstricturing/nonpenetrating, stricturing, and penetrating phenotypes. ${ }^{2}$ Half of the adult CD patients will have intestinal complications, such as strictures or fistulas, within 20 years after diagnosis. ${ }^{3}$ In addition, CD-related strictures often lead to significant complications such as bowel obstruction and need intensive treatment. Strictures in IBD can occur because of longstanding inflammation and are more commonly seen in CD compared with UC. $25 \%$ of CD patients have had at least one small bowel

Received September 10, 2014. Revised September 15, 2014. Accepted September 17, 2014

Correspondence to Shu-Chen Wei, Department of Internal Medicine, National Taiwan University Hospital and College of Medicine, No.7 Chung-

Shan South Road, Taipei 101, Taiwan. Tel: +886-2-23123456 ext. 65768,

Fax:+886-2-23947927,E-mail: shuchenwei@ntu.edu.tw

Financial support: None. Conflict of interest: None. stricture and $10 \%$ have had at least one colonic stricture. ${ }^{4}$ Most of these patients will require at least one surgery during their lifetime. ${ }^{5,6}$

Even with progress in modern therapies, such as immunosuppressants and biologics which are being used more frequently in treating $\mathrm{CD}$, there is no significant decrease in intestinal complications of $\mathrm{CD}$ and the need for surgery. ${ }^{7}$ The annual incidence of hospitalization is $20 \%$ and half of the patients need surgery due to intestinal complications, such as stricture, within 10 years after diagnosis and the risk of postoperative recurrence is $44-55 \%$ after 10 years. ${ }^{3,8}$ Moreover, stricture is one of the major factors for treatment failure or loss of response to biologics in treating CD patients. ${ }^{9}$ For better management of CD patients, it is very important to know how to diagnose and manage the intestinal stricture during the disease's course.

\section{INCIDENCE AND PREVALENCE}

Currently, in Asia UC is more common than CD, but with the increasing incidence and prevalence of CD in Asia, it is expected that in the future, $\mathrm{CD}$ might be more prevalent than UC, similar to the situation in Western countries. In Western countries, the incidence rates for CD ranges from 14.6 to 17.4

๑ Copyright 2015. Korean Association for the Study of Intestinal Diseases. All rights reserved.

This is an Open Access article distributed under the terms of the Creative Commons Attribution Non-Commercial License (http://creativecommons.org/licenses/by-nc/3.0)

which permits unrestricted non-commercial use, distribution, and reproduction in any medium, provided the original work is properly cited. 
per 100,000 person-years and the prevalence is from 155.2 to 279.2 per 100,000 people. A rising incidence and prevalence of $\mathrm{CD}$ has been reported in Asia. In Japan, the incidence of CD increased from 0.60 to 1.20 per 100,000 person-years from 1986 to 1998. The prevalence increased from 2.9 to 13.5 per 100,000 people between 1986 and 1998., ${ }^{1,10-14}$ In Korea, from 1986 to 2008 the incidence of CD increased from 0.53 per 100,000 person-years to 5.1 per 100,000 person-years. The prevalence rates of $\mathrm{CD}$ also dramatically increased, up to 11.24 per 100,000 people in $2008 .{ }^{15,16}$ In Taiwan, the incidence of CD increased from 0.19 per 100,000 person-years in 1998 to 0.24 per 100,000 person-years in 2008 . The prevalence of CD increased from 0.19 per 100,000 people in 1998 to 1.78 per 100,000 people in $2008 .{ }^{17}$

In a population-based cohort study, the cumulative probability of stricturing in CD after long term follow-up was $4.8 \%$ at day $90,7.2 \%$ at 1 year, $12.4 \%$ at 5 years, $15.2 \%$ at 10 years and $21.6 \%$ at 20 years, respectively. ${ }^{18}$ In another retrospective study from eight European referral centers which included 1,528 CD patients with more than 10 years of follow-up, $48.2 \%$ patient presented with stricturing behavior. ${ }^{19}$ In Japan, a hospital- based study with a 25 years follow-up period, the rate of stricturing in CD was $39.9 \%{ }^{20}$ In Korea, a hospitalbased study with a 16 year follow-up period, the rate of stricturing in CD was $20.1 \%{ }^{21}$ In Taiwan, a hospital-based study with 20 years follow-up, 33.6\% of CD patients presented with stricturing behavior. ${ }^{22}$

\section{PATHOPHYSIOLOGY}

Characteristically, cases of CD with intestinal strictures show thickening of all layers of the wall caused by accumulation of extracellular matrix (ECM) and expansion of mesenchymal cells. ${ }^{6,23}$ The pathophysiology of the CD-related intestinal stricture is not clear, and it is generally believed that strictures develop from prolonged inflammation and fibrosis leading to strictures.

The mechanisms of fibrosis are complex and include proliferation and migration of fibroblast. This is followed by stellate cells activation, and extraintestinal fibroblast recruitment. ${ }^{24}$ Fibroblast aggregations relate to the expression of profibrotic growth factors and ECM. ${ }^{6}$ In cases of persistent inflammation in the intestine, the fibroblasts become activated and basic fibroblast growth factor, platelet-derived growth factor, or the pro-inflammatory cytokines interleukin$1 \beta$ and tumor necrosis factor- $\alpha$ (TNF- $\alpha$ ) are induced. These pro-inflammatory cytokines then expand and increase the amounts of mediators, inducing local inflammation and
ECM proteins. Finally, intestinal tissue remodeling and fibrosis occurs which in turn leads to stricture formation. ${ }^{6,24,25}$ Although chronic inflammation plays a central role in the stricture process, other contributing factors that may predispose patients to strictures have not been well-defined and need to be further studied. ${ }^{26-28}$

\section{RISK FACTORS AND PREDICTORS OF INTESTI- NAL STRICTURE}

There are some genetic factors that may increase the susceptibility of developing $\mathrm{CD}$ and influence the disease's behavior. The carrying of nucleotide oligomerisation domain 2 (NOD2) variants ( $\mathrm{OR}=2.11$ for at least two risk alleles for any of the NOD2 variants) and Janus-associated kinase 2 (JAK2) are associated with stricturing behavior. ${ }^{19} \mathrm{CD}$ patients with NOD2/caspase-recruitment domain 15 (CARD15) mutations on both chromosomes have a 10 -fold greater risk of developing strictures compared with those carrying the single mutation. ${ }^{6,29,30}$

Previous studies demonstrated an association with ileal distribution and structuring behavior, particularly among patients with biallelic CARD15 mutations. ${ }^{6,19}$ In Asians, the genetic marker TNF superfamily 15 (TNFSF15) and a serological marker anti-Saccharomyces cerevisiae antibodies (ASCA) IgA are also related to complicated CD behavior. ${ }^{31}$

Apart from genetic and serological factors, the most common risk factors are clinical, environmental and endoscopic parameters. Age of diagnosis less than 40 years, perianal disease and the need for steroids during the first flare are the most prevalent clinical parameters for predicting intestinal stricture. A history of smoking is another risk factor for CD complications and progression from diagnosis to first stricture. In the endoscopic findings, deep mucosal ulcerations with locations in the small bowel have also been identified as predictive of a patient's progression to stricturing disease. ${ }^{32}$ Prior appendectomy and antimicrobial antibodies were also reported to be predictors of stricture. ${ }^{6,32}$

\section{DIAGNOSIS OF INTESTINAL STRICTURES IN CD PATIENTS}

$\mathrm{CD}$ is a clinical diagnosis that includes history and physical findings with objective data from imaging and laboratory studies. Once the diagnosis of CD is established, it is important to phenotype it according to the Montreal classification. ${ }^{3}$ To diagnose the stricture or not, we can use imaging tools, such transabdominal ultrasonography (TUS), CT, magnetic 
resonance (MR) enterography, and endoscopy.

\section{Transabdominal Ultrasonography}

TUS is a widely available, non-invasive technique for estimating the intestinal stricture in CD. Several studies have shown the utility of TUS for IBD. ${ }^{33-36}$ Intestinal wall thickness more than $4 \mathrm{~mm}$ can be considered a pathological change of IBD. A thickened, stiff bowel wall and narrowing of the intestinal lumen together with distended fluid, or echogenic content filled loops just above the thickened bowel segment can be found in strictures or stenosis. ${ }^{33}$ It is safe in young and pregnant patients without radiation and currently accepted as a first line tool in assessing patients with $\mathrm{CD}^{33,35}$ However, TUS is an operator-based technique.

The sensitivity and specificity in detecting CD by TUS were generally reported in the range from 73 to $96 \%$ and from 90 to $100 \%$, respectively. ${ }^{37}$ In a series of 296 consecutive patients with proven $\mathrm{CD}$, the sensitivity and specificity of TUS in the detection of strictures were $79 \%$ and $98 \%$ in nonoperative CD patients. In operative CD cases, the sensitivity and specificity were $90 \%$ and $100 \%$, respectively. ${ }^{33}$

The strictures could be due to acute inflammation with edematous or to spasmodic changes of the bowel. They are also be due to chronic fibrostenotic, fixed lesions. Inflammatory strictures are likely to respond to medical therapy, but symptomatic fibrotic strictures often require surgery. ${ }^{38,39}$ Recently, new techniques such as color Doppler imaging, harmonic imaging, panoramic imaging and contrast-enhanced ultrasound have increased the power of ultrasound in differentiating the stricture's etiology. ${ }^{3,36,37}$ During active CD inflammation, TUS shows intramural hypervascularisation in the color flow Doppler ultrasound. ${ }^{36}$ To differentiate between inflammatory and fibrotic strictures, contrast-enhancement ultrasound shows better intramural vascularization imaging than color flow Doppler ultrasound ${ }^{36}$ In a pilot study, transcutaneous ultrasound elasticity imaging was able to differentiate between fibrotic and unaffected intestines in patients with CD. Detection of decreased tissue strain is an accurate surrogate marker for intestinal fibrosis. ${ }^{38}$ However, further prospective clinical studies are needed to get firm conclusion.

\section{CT and MR Enterography}

CD typically presents with skip lesions and involves one or several intestinal segments. All of the involved segments could cause strictures. These strictures may vary in length from $2-3 \mathrm{~cm}$ to as long as $20-30 \mathrm{~cm}^{39}$ When using TUS, it is difficult to evaluate the relationship between the strictured loop and the adjacent bowel loops as well as the adjacent structures.

In this situation, cross-sectional imaging, such as CT or MRI, are the preferred imaging methods. CT or MR enterography of the small bowel have become widely accepted in diagnosing IBD and its related complications. These techniques can help to make the diagnosis, localize lesions, behavior, disease severity, inflammatory activity and the presence of extraintestinal complications. ${ }^{39}$ Both CT and MRI are reported to have a sensitivity of over $95 \%$ for the detection of $\mathrm{CD}^{40}$ One dilemma about using CT or MR enterography to diagnose the stricture is the extent of bowel distension found. In cases of underextension, the CT or MR enterography's power of predicting a stricture is affected and can confuse the results.

In general, CT enterography has been shown to have sen-
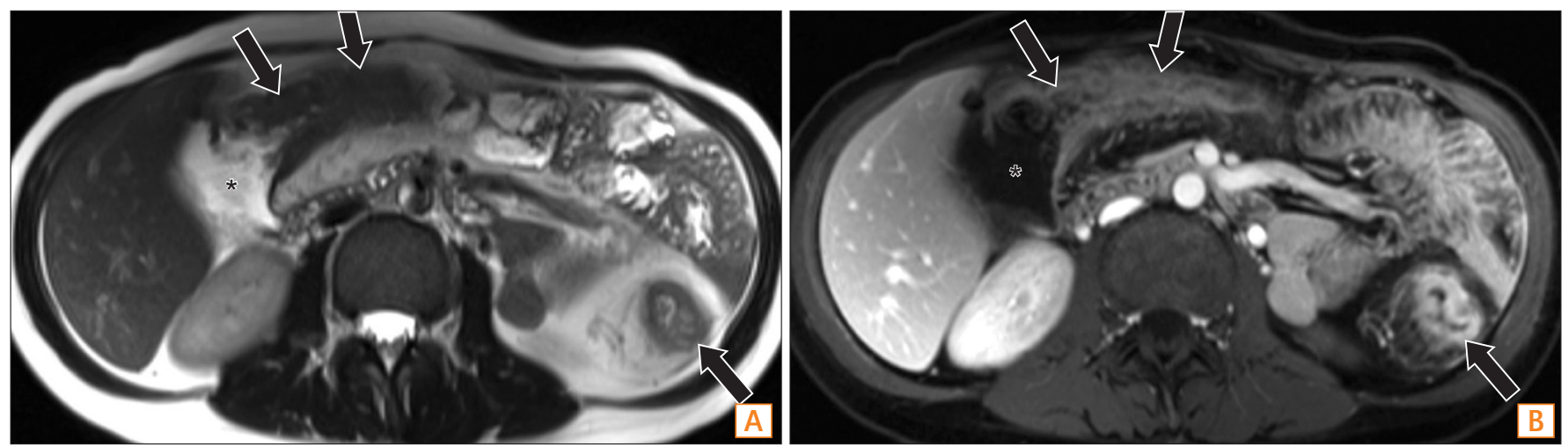

Fig. 1. A 33-year-old woman with CD who had active inflammation with stenosis. (A) An axial T2-weighted image and (B) an axial post-contrast T1weighted image show abnormal wall-thickening, increased enhancement, and adjacent fat-stranding of transverse and descending colon (arrows), suggestive of active inflammation. There is intestinal stenosis with dilated proximal colon ${ }^{*}$ ). 

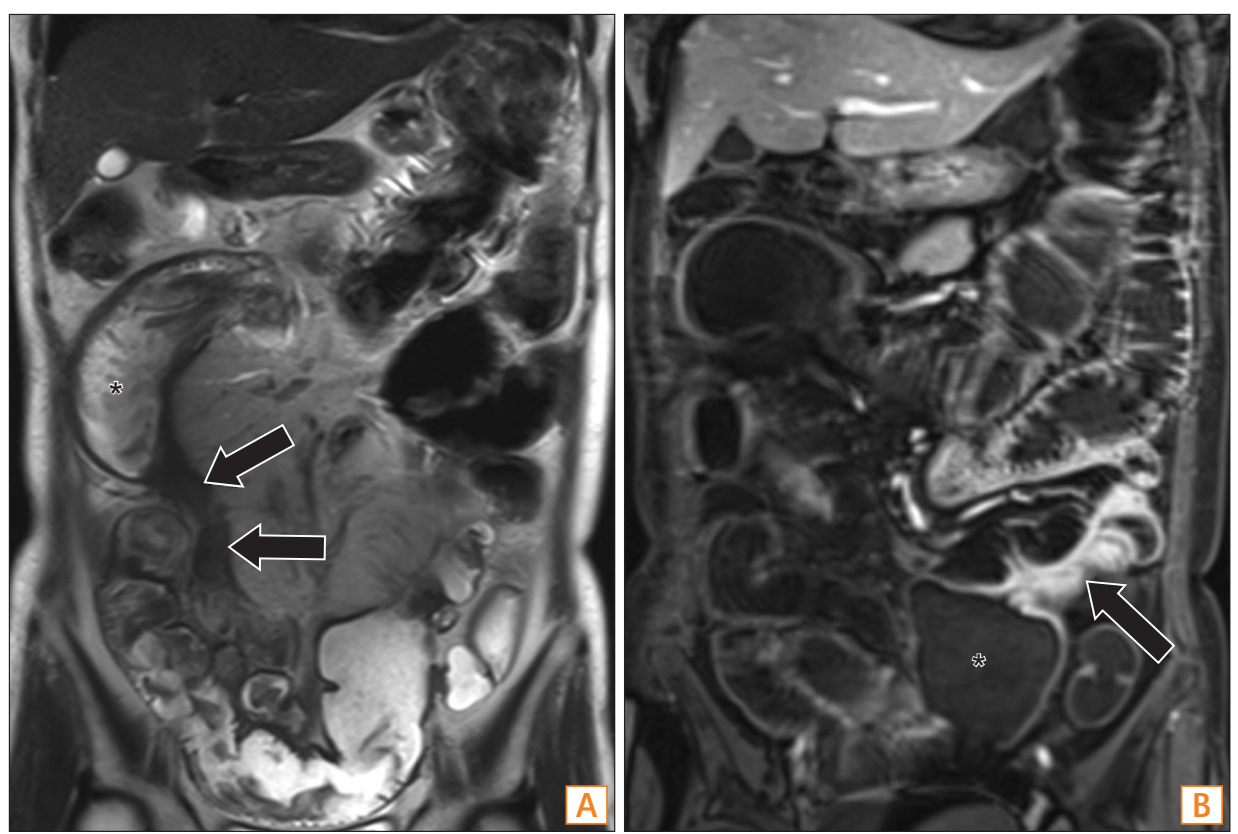

Fig. 2. A 57-year-old woman with $C D$ who had fibrosis with stricture. (A) A coronal T2weighted image shows an abnormal segment of the distal ileum (arrows) with wallthickening and luminal narrowing, with relative low signal and minimal inflammatory changes, suggestive of fibrosis. There is stricture with dilated proximal intestine (*). (B) A coronal post-contrast T1-weighted image shows another involved ileal segment at the left lower abdomen (arrow), with dilated proximal intestine ${ }^{*}$ ). The patient underwent an operation and fibrotic changes were confirmed.

sitivity for intestinal stricture/stenosis of $85-93 \%$ and specificity of $100 \%$. The sensitivity for MR enterography in the detection of stenosis/stricture ranges from $75 \%$ to $100 \%$ with a specificity of 91-100\%. ${ }^{32}$ With improved soft tissue contrast, MR enterography could be useful to differentiate between inflammation and fibrosis (Fig. 1 and 2). Image findings of decreased signal intensity on T2-weighted images and reduction of intestinal wall enhancement on post-contrast images are usually associated with fibrosis. ${ }^{41}$

\section{Endoscopy}

Ileocolonoscopy with biopsies is the gold standard for diagnosing and monitoring patients with $\mathrm{CD} .{ }^{3}$ However, owing to its invasive nature and cost, endoscopy (especially balloon-assisted enteroscopy [DBE]), is not an appropriate tool for screening CD patients. The use of biomarkers as surrogate markers of intestinal and systemic inflammation, such as CRP and faecal calprotectin, might help. ${ }^{42}$ However, in CD patients with suspected intestinal stricture from other examinations, endoscopy can make direct visual and histologic evaluations. ${ }^{4}$ In addition, endoscopy can confirm disease activity, severity of lesions, mucosal status, and also rule out malignancies by histological staining. ${ }^{42}$

The terminal ileum is the most common site for stricture formation and it is safe to perform an ileocolonoscopy there as an initial investigation. However, an ileocolonoscopy cannot reach lesions in the deep parts of the small bowel. The introduction of DBE, including single-balloon enteroscopy
Table 1. Sensitivity, Specificity for Detecting Stricture in CD in Different Imaging Tools

\begin{tabular}{lcc}
\hline \multicolumn{1}{c}{ Variables } & Sensitivity & Specificity \\
\hline Transabdominal ultrasonography $^{37}$ & $73-96$ & $90-100$ \\
CT enterography $^{32}$ & $85-93$ & 100 \\
Magnetic resonance enterography $^{32}$ & $75-100$ & $91-100$ \\
\hline
\end{tabular}

Values are presented as \%.

and DBE, has made previously difficult-to-reach parts of the small bowel possible to be evaluated. ${ }^{43}$ Capsule endoscopy can also visualize the whole small bowel, and its diagnostic yield in small-bowel lesions of CD has been well established. ${ }^{42}$ However, in cases of CD with intestinal stricture, capsule endoscopy is contraindicated, as the capsule may get stuck in the stricture area, leading to unnecessary and avoidable surgery for the patients.

\section{MANAGEMENT OF INTESTINAL STRICTURES IN CD}

In general, treatment of $\mathrm{CD}$ includes lifestyle changes, medical management, and surgical interventions when indicated. However, when strictures are diagnosed, treatment is not a clear cut issue. More than $80 \%$ of CD patients have at least one surgical resection within 10 years of their diagnosis, and most times, the operation is due to intestinal strictures. ${ }^{32}$

Management of CD-related strictures are dependent on the individual patients' situation. In the past, for CD patients with small intestine involvement, the primary surgical in- 
dications were intestinal obstruction (55\%), and intestinal fistula and abscess (32\%) ${ }^{44}$ In addition to steroids and 5 -aminosalicylates, the use of immunomodulators and antiTNF therapy, result in higher efficacies and improvements of medical treatments for CD patients. ${ }^{7}$ With the improvement of medical treatments, indication and necessity for CD patient surgery will probably be lower in the future. Currently, making the decision of whether the patient needs surgery or keep on medical treatment is a difficult question and often needs a multidisplinary evaluation.

\section{Medical Treatments}

Obviously, strictures are less responsive to medical treatments unless the stricture is mostly related to inflammation and not fibrosis. However, for decreasing, delaying or preventing strictures, the efficacy of medical treatments can possibly help but the picture is still not clear. Immunomodulators (such as azathioprine and methotrexate) have been used for CD over the last 25 years. However, the cumulative risk of developing intestinal strictures or penetrating complications remains unchanged. ${ }^{7}$ Anti-TNF- $\alpha$ monoclonal antibody is particularly effective in $\mathrm{CD}$ and the introduction of Infliximab in 1998 revolutionized the treatment of CD. The efficacy of anti-TNF- $\alpha$ treatment is not only to induce, but also to maintain, steroid-free remission. ${ }^{45}$

However, there may be some concern regarding the use of infliximab in patients with established strictures. Rapid mucosal healing may result together with excess scar tissue formation and strictures due to the antagonistic effect of TNF- $\alpha$ on transforming growth factor- $\beta$ signaling. ${ }^{6,32}$ In the Crohn's Therapy, Resource, Evaluation, and Assessment Tool (TREAT) registry and the A Crohn's Disease Clinical Trial Evaluating Infliximab in a New Long-Term Treatment Regimen (ACCENT I) infliximab maintenance trial, there was no increased risk of the clinical occurrence of strictures. ${ }^{26,32}$ The population-wide studies done on anti-TNF have not yet demonstrated a decrease in the need for surgery and further studies are warranted and expected. ${ }^{45}$

Up to $40 \%$ of CD patients will eventually need secondary surgery, therefore, it is important to avoid recurrent strictures. ${ }^{45}$ Recurrence is most common in the neoterminal ileum immediately proximal to the anastomosis. ${ }^{6}$ The advent of anti-TNF agents and their demonstrated effect on mucosal healing in the preoperative setting has given hope to physicians that relapses can be avoided when administered postoperatively. ${ }^{45}$ The positive impact of infliximab in avoiding postoperative recurrence has been demonstrated. The study showed a postoperative recurrence rate of $9.1 \%(1 / 11)$ in the infliximab group and $84.6 \%(11 / 13)$ in the control group. ${ }^{46}$

\section{Endoscopy}

CD- related intestinal strictures show a poor response to medical treatments in general, and bowel resection or strictureplasty are often required. ${ }^{47}$ Balloon dilatation can delay or avoid surgery with either initial or recurrent strictures. Dilation of Crohn's strictures with endoscopy is widely used, but repeat dilations or surgery may be needed. Adjuvant intramural or topical steroid and azathioprine administration have been used with some success, but a formal randomized evaluation is needed. ${ }^{6,48,49}$ In general, the indication of balloon dilatation including symptomatic stricture is less than $4-5 \mathrm{~cm}$ without fistula, abscess or malignant formation. ${ }^{5}$

In a systemic review, endoscopic dilatation for CD-related strictures can achieve $86 \%$ success rate with long-term clinical efficacy in $58 \%$ of the patients. In addition, a stricture length less than $4 \mathrm{~cm}$ was associated with a good surgeryfree outcome. ${ }^{50}$ However most studies that discuss CD-related strictures are in the colon and ileocecal area. There are few reports that discuss strictures in the intestine, because of the difficulty in approaching that area. Recently, due to DBE, that has changed. DBE-assisted intestinal stricture dilation for $\mathrm{CD}$ is a procedure with significant benefits and should be considered as a useful and effective alternative to surgery. ${ }^{43}$

In previous studies, intestinal strictures longer than 4-5 $\mathrm{cm}$, severely inflamed with ulcers were considered high risk and a potential contraindication to DBE-assisted balloon dilation. ${ }^{43,50,51}$ In CD-related strictures in the colon, endoscopic treatment was $76 \%$ successful and surgery was required only in $2 \%$. However, failure of dilatation was observed in longsegment strictures of the terminal ileum. ${ }^{52,53}$ In one study of a total 13 procedures with DBE dilatation in 11 consecutive patients, the success rate was $72.7 \%$ and one case had delayed perforation. ${ }^{43}$ However, further studies are necessary due to the small case number.

Endoscopic stents have been explored in CD strictures. Self-expandable metal stents are now available for CDrelated stricture. Usually, self-expandable metal stent is not recommended in benign cases, since it entails the possible problem such as migration of the stent and bowel perforation, and that may limit the clinical application. ${ }^{5}$ Angular positioning of the stent will increase the risk of bowel perforation. ${ }^{54}$ In one study of 11 CD-related strictures, seven cases were post-operative stricture in the ileo-colonic anastomosis. Except for two cases with stent migration, five cases had long 
term symptom-free outcomes. ${ }^{55}$

\section{Surgery}

Surgical treatment plays an important role in managing the stricture of CD patients, especially when the stricture location is not accessible by endoscopy or the patients were evaluated as high risk/contraindicated for endoscopic dilatation. Despite the use of appropriate medical therapy, small bowel strictures remain a major cause of morbidity in CD. These affect more than one third of patients with CD and often cause strictures and obstructions leading to hospitalization. ${ }^{43}$ The experience from a large tertiary care center in Pittsburgh showed that the rate of small bowel resection has remained unchanged over the years. Moreover, the relative frequency of intestine stricture and penetrating disease did not change over time. ${ }^{56}$

Laparoscopic surgery may have advantages by reducing postoperative adhesion formation. However, disease-related complications of CD increase the operative time and the conversion rates for a laparoscopic approach. ${ }^{6,57,58}$ Strictureplasty is also a potential option for stricture in CD patients with multiple previous surgeries. It is a useful surgical procedure for the CD strictures which could help in preserving intestinal length. ${ }^{59}$ Strictureplasty has been shown with $18 \%$ morbidity and $34 \%$ operative recurrence rates, which could achieve the comparative outcomes as the traditional surgery. ${ }^{60}$

\section{CONCLUSIONS}

Optimizing the medical treatment to prevent the occurrence or recurrence is the best strategy for managing strictures in CD patients. Evaluation of patients with a suspicion of a stricture can be done by ultrasound, CT or MR enterography imaging, which have high diagnostic sensitivity and specificity. Endoscopic or surgical intervention for the stricture should be evaluated and discussed with the patients. For high risk lesions or inaccessible strictures, less invasive but effective surgical approaches remain the preferred method of treatment.

\section{REFERENCES}

1. Prideaux L, Kamm MA, De Cruz PP, Chan FK, Ng SC. Inflammatory bowel disease in Asia: a systematic review. J Gastroenterol Hepatol 2012;27:1266-1280.
2. Silverberg MS, Satsangi J, Ahmad T, et al. Toward an integrated clinical, molecular and serological classification of inflammatory bowel disease: report of a Working Party of the 2005 Montreal World Congress of Gastroenterology. Can J Gastroenterol 2005;19(Suppl A):5A-36A.

3. Baumgart DC, Sandborn WJ. Crohn's disease. Lancet 2012;380: 1590-1605.

4. Chan G, Fefferman DS, Farrell RJ. Endoscopic assessment of inflammatory bowel disease: colonoscopy/esophagogastroduodenoscopy. Gastroenterol Clin North Am 2012;41:271-290.

5. Paine E, Shen B. Endoscopic therapy in inflammatory bowel diseases (with videos). Gastrointest Endosc 2013;78:819-835.

6. Burke JP, Mulsow JJ, O'Keane C, Docherty NG, Watson RW, O'Connell PR. Fibrogenesis in Crohn's disease. Am J Gastroenterol 2007;102:439-448.

7. Cosnes J, Nion-Larmurier I, Beaugerie L, Afchain P, Tiret E, Gendre JP. Impact of the increasing use of immunosuppressants in Crohn's disease on the need for intestinal surgery. Gut 2005;54: 237-241.

8. Peyrin-Biroulet L, Loftus EV, Jr., Colombel JF, Sandborn WJ. The natural history of adult Crohn's disease in population-based cohorts. Am J Gastroenterol 2010;105:289-297.

9. Ben-Horin S, Chowers Y. Review article: loss of response to antiTNF treatments in Crohn's disease. Aliment Pharmacol Ther 2011;33:987-995.

10. Morita N, Toki S, Hirohashi T, et al. Incidence and prevalence of inflammatory bowel disease in Japan: nationwide epidemiological survey during the year 1991. J Gastroenterol 1995;30(Suppl 8):1-4.

11. Kitahora T, Utsunomiya T, Yokota A. Epidemiological study of ulcerative colitis in Japan: incidence and familial occurrence. The Epidemiology Group of the Research Committee of Inflammatory Bowel Disease in Japan. J Gastroenterol 1995;30(Suppl 8):5-8.

12. Yao T, Matsui T, Hiwatashi N. Crohn's disease in Japan: diagnostic criteria and epidemiology. Dis Colon Rectum 2000;43:S85S93.

13. Higashi A, Watanabe Y, Ozasa K, Hayashi K, Aoike A, Kawai K. Prevalence and mortality of ulcerative colitis and Crohn's disease in Japan. Gastroenterol Jpn 1988;23:521-526.

14. Asakura K, Nishiwaki Y, Inoue N, Hibi T, Watanabe M, Takebayashi T. Prevalence of ulcerative colitis and Crohn's disease in Japan. J Gastroenterol 2009;44:659-665.

15. Shin DH, Sinn DH, Kim YH, et al. Increasing incidence of inflammatory bowel disease among young men in Korea between 2003 and 2008. Dig Dis Sci 2011;56:1154-1159. 
16. Yang SK, Yun S, Kim JH, et al. Epidemiology of inflammatory bowel disease in the Songpa-Kangdong district, Seoul, Korea, 1986-2005: a KASID study. Inflamm Bowel Dis 2008;14:542549.

17. Wei SC, Lin MH, Tung CC, et al. A nationwide population-based study of the inflammatory bowel diseases between 1998 and 2008 in Taiwan. BMC Gastroenterol 2013;13:166.

18. Yamamoto T, Watanabe T. Surgery for luminal Crohn's disease. World J Gastroenterol 2014;20:78-90.

19. Cleynen I, Gonzalez JR, Figueroa C, et al. Genetic factors conferring an increased susceptibility to develop Crohn's disease also influence disease phenotype: results from the IBDchip European Project. Gut 2013;62:1556-1565.

20. Yano Y, Matsui T, Hirai F, et al. Cancer risk in Japanese Crohn's disease patients: investigation of the standardized incidence ratio. J Gastroenterol Hepatol 2013;28:1300-1305.

21. Ye BD, Yang SK, Cho YK, et al. Clinical features and long-term prognosis of Crohn's disease in Korea. Scand J Gastroenterol 2010;45:1178-1185.

22. Wei SC, Ni YH, Yang HI, et al. A hospital-based study of clinical and genetic features of Crohn's disease. J Formos Med Assoc 2011;110:600-606.

23. Rieder F, Fiocchi C. Mechanisms of tissue remodeling in inflammatory bowel disease. Dig Dis 2013;31:186-193.

24. Rieder F, Fiocchi C. Intestinal fibrosis in inflammatory bowel disease - Current knowledge and future perspectives. J Crohns Colitis 2008;2:279-290.

25. Armaka M, Apostolaki M, Jacques P, Kontoyiannis DL, Elewaut D, Kollias G. Mesenchymal cell targeting by TNF as a common pathogenic principle in chronic inflammatory joint and intestinal diseases. J Exp Med 2008;205:331-337.

26. Lichtenstein GR, Olson A, Travers S, et al. Factors associated with the development of intestinal strictures or obstructions in patients with Crohn's disease. Am J Gastroenterol 2006;101: 1030-1038.

27. Gelbmann CM, Mestermann S, Gross V, Kollinger M, Scholmerich J, Falk W. Strictures in Crohn's disease are characterised by an accumulation of mast cells colocalised with laminin but not with fibronectin or vitronectin. Gut 1999;45:210-217.

28. Graham MF. Pathogenesis of intestinal strictures in Crohn's disease-an update. Inflamm Bowel Dis 1995;1:220-227.

29. Hugot JP, Laurent-Puig P, Gower-Rousseau C, et al. Mapping of a susceptibility locus for Crohn's disease on chromosome 16. Nature 1996;379:821-823.

30. Hugot JP. Genetic origin of IBD. Inflamm Bowel Dis 2004;10 (Suppl 1):S11-S15.
31. Tung CC, Wong JM, Lee WC, et al. Combining TNFSF15 and ASCA IgA can be used as a predictor for the stenosis/perforating phenotype of Crohn's disease. J Gastroenterol Hepatol 2014; 29:723-729.

32. Rieder F, Zimmermann EM, Remzi FH, Sandborn WJ. Crohn's disease complicated by strictures: a systematic review. Gut 2013;62:1072-1084.

33. Parente F, Maconi G, Bollani S, et al. Bowel ultrasound in assessment of Crohn's disease and detection of related small bowel strictures: a prospective comparative study versus $\mathrm{x}$ ray and intraoperative findings. Gut 2002;50:490-495.

34. Migaleddu V, Scanu AM, Quaia E, et al. Contrast-enhanced ultrasonographic evaluation of inflammatory activity in Crohn's disease. Gastroenterology 2009;137:43-52.

35. Horsthuis K, Bipat S, Bennink RJ, Stoker J. Inflammatory bowel disease diagnosed with US, MR, scintigraphy, and CT: metaanalysis of prospective studies. Radiology 2008;247:64-79.

36. Kralik R, Trnovsky P, Kopáčová M. Transabdominal ultrasonography of the small bowel. Gastroenterol Res Pract doi: 10.1155/2013/896704. Published online 19 November 2013.

37. Dietrich CF. Significance of abdominal ultrasound in inflammatory bowel disease. Dig Dis 2009;27:482-493.

38. Stidham RW, Xu J, Johnson LA, et al. Ultrasound elasticity imaging for detecting intestinal fibrosis and inflammation in rats and humans with Crohn's disease. Gastroenterology 2011;141:819826.

39. Masselli G, Gualdi G. CT and MR enterography in evaluating small bowel diseases: when to use which modality? Abdom Imaging 2013;38:249-259.

40. Furukawa A, Saotome T, Yamasaki M, et al. Cross-sectional imaging in Crohn disease. Radiographics 2004;24:689-702.

41. Fiorino G, Bonifacio C, Malesci A, Balzarini L, Danese S. MRI in Crohn's disease--current and future clinical applications. Nat Rev Gastroenterol Hepatol 2012;9:23-31.

42. Benitez JM, Meuwis MA, Reenaers C, Van Kemseke C, Meunier $\mathrm{P}$, Louis E. Role of endoscopy, cross-sectional imaging and biomarkers in Crohn's disease monitoring. Gut 2013;62:1806-1816.

43. Despott EJ, Gupta A, Burling D, et al. Effective dilation of smallbowel strictures by double-balloon enteroscopy in patients with symptomatic Crohn's disease (with video). Gastrointest Endosc 2009;70:1030-1036.

44. Farmer RG, Hawk WA, Turnbull RB, Jr. Indications for surgery in Crohn's disease: analysis of 500 cases. Gastroenterology 1976; 71:245-250.

45. de Buck van Overstraeten A, Wolthuis A, D'Hoore A. Surgery for Crohn's disease in the era of biologicals: a reduced need or delayed verdict? World J Gastroenterol 2012;18:3828-3832. 
46. Regueiro M, Schraut W, Baidoo L, et al. Infliximab prevents Crohn's disease recurrence after ileal resection. Gastroenterology 2009;136:441-450.

47. de'Angelis N, Carra MC, Borrelli O, et al. Short- and long-term efficacy of endoscopic balloon dilation in Crohn's disease strictures. World J Gastroenterol 2013;19:2660-2667.

48. Van Assche G, Geboes K, Rutgeerts P. Medical therapy for Crohn's disease strictures. Inflamm Bowel Dis 2004;10:55-60.

49. Brooker JC, Beckett CG, Saunders BP, Benson MJ. Long-acting steroid injection after endoscopic dilation of anastomotic Crohn's strictures may improve the outcome: a retrospective case series. Endoscopy 2003;35:333-337.

50. Hassan C, Zullo A, De Francesco V, et al. Systematic review: Endoscopic dilatation in Crohn's disease. Aliment Pharmacol Ther 2007;26:1457-1464.

51. Hoffmann JC, Heller F, Faiss S, et al. Through the endoscope balloon dilation of ileocolonic strictures: prognostic factors, complications, and effectiveness. Int J Colorectal Dis 2008;23:689696.

52. Kwon YH, Jeon SW, Lee YK. Endoscopic management of refractory benign colorectal strictures. Clin Endosc 2013;46:472-475.

53. Bonin EA, Baron TH. Update on the indications and use of colonic stents. Curr Gastroenterol Rep 2010;12:374-382.
54. Lee JG, Yoo KH, Kwon CI, Ko KH, Hong SP. Angular positioning of stent increases bowel perforation after self-expandable metal stent placement for malignant colorectal obstruction. Clin Endosc 2013;46:384-389.

55. Rejchrt S, Kopacova M, Brozik J, Bures J. Biodegradable stents for the treatment of benign stenoses of the small and large intestines. Endoscopy 2011;43:911-917.

56. Lazarev M, Ullman T, Schraut WH, Kip KE, Saul M, Regueiro M. Small bowel resection rates in Crohn's disease and the indication for surgery over time: experience from a large tertiary care center. Inflamm Bowel Dis 2010;16:830-835.

57. Casillas S, Delaney CP. Laparoscopic surgery for inflammatory bowel disease. Dig Surg 2005;22:135-142.

58. Casillas S, Delaney CP, Senagore AJ, Brady K, Fazio VW. Does conversion of a laparoscopic colectomy adversely affect patient outcome? Dis Colon Rectum 2004;47:1680-1685.

59. Cima RR, Wolff BG. Reoperative Crohn's surgery: tricks of the trade. Clin Colon Rectal Surg 2007;20:336-343.

60. Dietz DW, Laureti S, Strong SA, et al. Safety and longterm efficacy of strictureplasty in 314 patients with obstructing small bowel Crohn's disease. J Am Coll Surg 2001;192:330-337, discussion 337-338. 